\title{
Intention to seek emergency medical services during community overdose events in British Columbia, Canada: A cross-sectional survey
}

\author{
Brad Kievit \\ University of British Columbia \\ Jessica Xavier \\ British Columbia Centre for Disease Control \\ Max Ferguson \\ British Columbia Centre for Disease Control \\ Heather Palis \\ British Columbia Centre for Disease Control

\section{Soroush Moallef} \\ Simon Fraser University

\section{Amanda Slaunwhite} \\ British Columbia Centre for Disease Control

\section{Terri Gillis} \\ Métis Nation British Columbia \\ Rajmeet Virk \\ Métis Nation British Columbia \\ Jane A Buxton ( $\sigma$ jane.buxton@bccdc.ca ) \\ University of British Columbia
}

\section{Research Article}

Keywords: 911-calling, Drug Overdose, Good Samaritan Law, Emergency medical services, Decriminalization, Harm reduction

Posted Date: February 8th, 2022

DOl: https://doi.org/10.21203/rs.3.rs-1328199/v1

License: @ (1) This work is licensed under a Creative Commons Attribution 4.0 International License. Read Full License

Version of Record: A version of this preprint was published at Substance Abuse Treatment, Prevention, and Policy on July 26 th, 2022. See the published version at https://doi.org/10.1186/s13011-022-00484-0. 


\section{Abstract}

Introduction: Canada and the United States continue to experience increasing overdose deaths attributed to highly toxic illicit substances. Many bystanders report being hesitant to call 9-1-1 at an overdose due to fears around police presence and arrests. In Canada, a federal law was enacted in 2017, the Good Samaritan Drug Overdose Act (GSDOA), to provide protection from simple drug possession and related charges when 9-1-1 is called to an overdose. There is limited evidence, however, that the GSDOA has improved rates of 9-1-1-calling at overdose events. We therefore sought to examine intent to call 9-1-1 among persons who received GSDOA education and were at risk of witnessing an overdose.

Methods: A cross-sectional survey was conducted with people at risk of witnessing an overdose recruited at 19 Take Home Naloxone (THN) program sites across British Columbia as well as online through Foundry from October 2020 to April 2021. Descriptive statistics were used to examine intention to call 9-1-1 at future overdoses. Multivariable logistic regression models were built in hierarchical fashion to examine factors associated with intention to call 9-1-1.

Results: Overall, $89.6 \%(n=404)$ of the eligible sample reported intention to call 9-1-1. In the multivariable model, factors positively associated with intention to call 9-1-1 included identifying as a cisgender woman (adjusted odds ratio [AOR]: 3.37; 95\% Cl: 1.19-9.50) and having previous GSDOA awareness ([AOR]: 4.16; 95\% Cl: 1.62-10.70). Having experienced a stimulant overdose in the past 6 months was negatively associated with intention to call 9-1-1 ([AOR]: 0.24; 95\% Cl: 0.09-0.65).

Conclusion: A small proportion of the respondents reported that the GSDOA did not affect their intention to call 9-1-1. Our findings reveal that some people who use drugs continue to face barriers to calling 9-1-1, suggesting that participants perceived that the GSDOA offers limited legal protections. Increasing GSDOA awareness and/or additional interventions to support the aims of the GSDOA, such as implementing broader decriminalization of drug possession, could address ongoing barriers to emergency medical care for people who use drugs.

\section{Background}

Canada and the United States (US) have experienced an increasingly pervasive drug toxicity crisis over recent years $[1,2]$. The province of British Columbia (BC) has consistently reported the highest rates of illicit drug toxicity deaths of any province in Canada since 2016[1]. Contamination of the illicit drug supply with fentanyl (a synthetic opioid) and its analogues have been key drivers of the crisis[3]. The detected presence of fentanyl among illicit drug toxicity deaths increased from $5 \%$ in 2012 to $85 \%$ in 2020 , which coincides with a more than five-fold increase in overdose deaths over the same period of time[4].

Since BC declared a public health emergency of illicit drug toxicity (overdose) deaths in April 2016[5], a key aspect of the public health response has been to expand the distribution of naloxone, an inhibitor of $\mu$-opioid receptors that can reverse the respiratory depression associated with an opioid-induced overdose[6], through the community-based Take Home Naloxone (THN) program[7]. As of August 2021, there are 1,884 active THN distribution sites in BC, which include: harm reduction sites (e.g., harm reduction supply distribution sites and observed consumption sites)[8], hospitals (i.e., all emergency departments), provincial correctional facilities for people on release, community pharmacies, and other sites frequented by people who use substances[9]. These sites provide overdose prevention, recognition, and response training along with low-barrier access to naloxone kits at no cost to individuals at risk of witnessing an overdose. Alongside administering naloxone, THN training emphasizes calling an emergency number, 9-1-1, to alert emergency medical services (EMS) as one of the primary responses to an overdose. Seeking medical services is particularly important, given potent opioids can have a longer duration of effect than naloxone, and there is a risk of reverting back into a state of overdose even after receiving naloxone or experiencing other adverse effects of overdose[10-12].

Despite recommendations to call 9-1-1 when witnessing an overdose, studies in BC have found that bystanders often delay or avoid contacting EMS, with 9-1-1 being called about half of the time[13, 14]. Some of the most commonly reported deterrents to calling 9-1-1 include fears of arrest, general concern of police involvement, previous negative experiences with first responders, and fears around losing housing or custody of children[15-18]. Fears and concerns are especially prominent in youth as studies have found they are more commonly targeted by police compared to adults and are likely to perceive police authority as negative and unpredictable[1921]. In BC, interventions to reduce these barriers have included a regional overdose non-informing policy put in place by the Vancouver Police Department in 2006 followed by a province wide police non-informing policy initiated by BC Emergency Health Services (BCEHS) in 2016[22, 23]. Research conducted in the province suggested that these policies decreased police attendance at overdoses 
and reduced the proportion of bystanders who reported fears of police presence as a barrier to calling 9-1-1[13, 23]. However, the noninforming policies did not result in an increased likelihood of bystanders calling 9-1-1[13]. To further encourage overdose bystanders to contact EMS, the Canadian federal government introduced the Good Samaritan Drug Overdose Act (GSDOA) in 2017[24]. Under this legislation, any person at the scene of an overdose, including the person having the overdose, is protected from charges for simple possession of a controlled substance when 9-1-1 is called. Additionally, the GSDOA protects people with prior charges and conditions related to simple possession, such as breach of probation.

The current evidence on the effectiveness of the GSDOA and other similar drug related Good Samaritan laws in the US is limited[25]. This has been attributed, in part, to low levels of awareness and understanding of drug related Good Samaritan laws among police officers and people who use drugs (PWUD)[26-29]. Studies comparing overdose mortality across multiple states have had mixed results, where only one of three shows a significant reduction in fatal overdoses in regions where a drug related Good Samaritan law has been enacted[30-32]. Among PWUD and police officers in BC, there is moderate awareness of the GSDOA; however, accurate understanding of the Act is low[28, 29,33]. Even among persons who are aware of their local drug related Good Samaritan law, attitudes and perceptions of its effectiveness are not always positive[17]. A study conducted in BC found that police officers did not have an accurate understanding of the GSDOA and reported exercising their discretion to interpret the Act, leading to inconsistencies in its implementation[29]. PWUD also face social and structural barriers to accessing health services, such as stigma, which are not accounted for by Good Samaritan laws[34-36]. It is likely that some populations who are at risk of witnessing an overdose are not being effectively served by drug related Good Samaritan laws despite their awareness of the law[33].

Utilizing data from a cross-sectional survey administered across 19 THN program sites in BC, our aim was to investigate factors associated with intention to call 9-1-1 among people who have received education about the GSDOA. Our findings can inform targeted initiatives to increase GSDOA awareness and address barriers to calling 9-1-1.

\section{Methods}

\section{Study Design \& Data Collection}

This study used data from the BC Centre for Disease Control's (BCCDC) GSDOA Survey, administered from October 2020 to April 2021 (See Additional File 1). A cross-sectional survey was designed collaboratively by a team of researchers, regional health authority representatives, harm reduction coordinators, people with lived and living experience (PWLLE) of substance use, youth organizations and youth representatives. Research team members at Foundry, a provincial network of health and social services for youth, provided input throughout the study and members of the Youth4Youth advisory group provided input as youth representatives. Findings were also presented to the Métis Nation of $\mathrm{BC}$ as well as peer groups which include the Professionals for Ethical Engagement of Peers (PEEP) and Peer2Peer Project (P2P), and their feedback was incorporated into our analysis and interpretation of findings.

Using input from regional harm reduction coordinators, 19 THN sites with sufficient capacity (staff and physical space accounting for COVID-19 guidelines i.e. physical distancing) from across the province were invited and agreed to participate. In-person survey participants $(n=416)$ were provided $\$ 10$ CAD and an additional \$5 CAD was provided to the participating THN site for each participant enrolled. An online version of the survey was available through Qualtrics [37]. This was offered as an option to respond by THN sites and was advertised by Foundry to recruit youth participants, who were defined as 16-24 years old [38]. Persons completing the survey online $(n=77)$ were offered participation in a raffle for a 1 in 10 chance of obtaining a $\$ 50$ VISA gift card. Eligibility criteria at THN sites were age (18 years and over) and being at risk of witnessing an overdose. This included PWLLE, peer responders and family or friends of people who use drugs as these individuals have a higher likelihood of witnessing an overdose [39-41]. Institutional ethics approval was obtained through the University of British Columbia's Behavioural Research Ethics Board (\# H19-01842).

\section{Study Variables}

\section{Outcome Variable}

The primary outcome variable for this study was "Intention to call 9-1-1 at an overdose event". After being provided with a definition of the GSDOA (Figure 1), participants were asked "Based on this description, if you were to witness someone overdose in the future,

Page $3 / 21$ 
would you call 9-1-1?" to which they could answer one of "yes", "no" or "prefer not to say". Included in the question was the note "Disclaimer: We cannot guarantee that police and emergency health responders will be knowledgeable about the GSDOA and will follow the Act."

\section{Explanatory Variables}

Explanatory variables of interest included participants' sociodemographic and substance use characteristics as well as variables that reflected participants' GSDOA knowledge and awareness. Sociodemographic characteristics included age group (16-24, 25-34, 35-54, $\geq 55$ years), gender (cisgender men, cisgender women, transgender and gender expansive [trans-men, trans-women, gender nonbinary], prefer not to say), Indigenous identity (non-Indigenous, Indigenous [First Nations, Métis, Inuit], prefer not to say), geographic health region as defined by the five health authorities within the province (Fraser Health, Interior Health, Island Health, Northern Health, Vancouver Coastal Health), employment status (yes, no, prefer not to say), housing status (private alone, private with other(s), supportive or unstable housing [hotel, motel, rooming house, single room occupancy, shelter], homeless, prefer not to say) and cellphone possession (yes, no, prefer not to say). Due to a small number of participants reporting gender identity as "trans and gender expansive", we excluded this group and used a binary gender identity variable of "cis man" and "cis woman" for statistical analyses, though they were retained for descriptive analysis (Table 1).

Table 1

Demographics of the GSDOA Survey $(2020$ - 2021) by the BC health regions $(\mathrm{N}=493)$. 


\begin{tabular}{|c|c|c|c|c|c|c|}
\hline $\begin{array}{l}\text { Demographic } \\
\text { Characteristics }\end{array}$ & $\begin{array}{l}\text { Fraser } \\
\text { Health } \\
n(\text { row \%) }\end{array}$ & $\begin{array}{l}\text { Interior } \\
\text { Health } \\
n \text { (row \%) }\end{array}$ & $\begin{array}{l}\text { Island } \\
\text { Health } \\
n \text { (row \%) }\end{array}$ & $\begin{array}{l}\text { Northern } \\
\text { Health } \\
n \text { (row \%) }\end{array}$ & $\begin{array}{l}\text { Vancouver Coastal } \\
\text { Health } \\
n(\text { row \%) }\end{array}$ & $\begin{array}{l}\text { Total } \\
N(\text { column } \\
\%)\end{array}$ \\
\hline Participants & $104(21.1)$ & $128(26.0)$ & $100(20.3)$ & $46(9.3)$ & $115(23.3)$ & $493(100)$ \\
\hline \multicolumn{7}{|l|}{ Age (years) } \\
\hline $16-24$ years & $16(14.2)$ & $14(12.4)$ & $17(15.0)$ & $9(8.0)$ & $57(50.4)$ & $113(22.9)$ \\
\hline $25-34$ years & $22(23.7)$ & $25(26.9)$ & $24(25.8)$ & $9(9.7)$ & $13(14.0)$ & $93(18.9)$ \\
\hline $35-44$ years & $25(23.4)$ & $36(33.6)$ & $23(21.5)$ & $10(9.3)$ & $13(12.1)$ & 107 (21.7) \\
\hline $45-54$ years & $17(17.3)$ & $30(30.6)$ & $24(24.5)$ & $12(12.2)$ & $15(15.3)$ & $98(19.9)$ \\
\hline 55 years and over & $20(28.2)$ & $20(28.2)$ & $11(15.5)$ & $5(7.0)$ & $15(21.1)$ & $71(14.4)$ \\
\hline Unknown & $4(36.4)$ & $3(27.3)$ & $1(9.1)$ & $1(9.1)$ & $2(18.2)$ & $11(2.2)$ \\
\hline \multicolumn{7}{|l|}{ Gender identity } \\
\hline Cis man & $62(22.0)$ & $79(28.0)$ & $61(21.6)$ & $21(7.4)$ & $59(20.9)$ & $282(57.2)$ \\
\hline Cis woman & $37(20.1)$ & $46(25.0)$ & $35(19.0)$ & $24(13.0)$ & $42(22.8)$ & $184(37.3)$ \\
\hline $\begin{array}{l}\text { Trans and gender } \\
\text { expansive a }\end{array}$ & $4(17.4)$ & $3(13.0)$ & $3(13.0)$ & $1(4.3)$ & $12(52.2)$ & $23(4.7)$ \\
\hline Unknown & $1(25.0)$ & $0(0.0)$ & $1(25.0)$ & $0(0.0)$ & $2(50.0)$ & $4(0.8)$ \\
\hline \multicolumn{7}{|l|}{ Indigenous identityb } \\
\hline First Nations & $25(18.8)$ & $30(22.6)$ & $19(14.3)$ & $20(15.0)$ & $39(29.3)$ & $133(27.0)$ \\
\hline Métis & $12(19.4)$ & $21(33.9)$ & $11(17.7)$ & $13(21.0)$ & $5(8.1)$ & $62(12.6)$ \\
\hline Inuit & $2(66.7)$ & $0(0.0)$ & $1(33.3)$ & $0(0.0)$ & $0(0.0)$ & $3(0.6)$ \\
\hline Non-indigenous & $54(21.4)$ & $60(23.8)$ & $63(25.0)$ & $10(4.0)$ & $65(25.8)$ & $252(51.1)$ \\
\hline Unknown & $11(25.6)$ & 17 (39.5) & $6(14.0)$ & $3(7.0)$ & $6(14.0)$ & $43(8.7)$ \\
\hline \multicolumn{7}{|c|}{$\begin{array}{l}\text { Health regions in increasing order of population are: Northern Health, Interior Health, Island Health, Vancouver Coas } \\
\text { Fraser Health. } \\
\text { a "Trans and gender expansive" identities include trans man, trans woman and gender non-conforming people. } \\
\text { b The authors recognize that Indigenous identity is often a proxy for factors associated with colonialism including } \\
\text { intergenerational trauma, systemic racism, criminalization and discrimination. }\end{array}$} \\
\hline
\end{tabular}

Indigenous identity is understood to act as a proxy for factors associated with colonialism including intergenerational trauma, systemic racism, criminalization and discrimination [42-45]. Descriptive analyses of First Nations, Métis, Inuit, and non-Indigenous identity were included in recognition of the heterogeneity of Indigenous peoples and their experiences (Table 1). However, Indigenous identity was dichotomized to maintain sample size in statistical analysis and regression models (Table 2 and 3 ).

Table 2

Factors associated with intention to call 9-1-1 at a future overdose among survey respondents. 


\begin{tabular}{|c|c|c|c|c|}
\hline & \multicolumn{4}{|c|}{ Intention to call 9-1-1 at overdose events } \\
\hline & Yes & No & Total & P-value ${ }^{a}$ \\
\hline & $(\mathrm{N}=404)$ & $(\mathrm{N}=47)$ & $(\mathrm{N}=451)$ & \\
\hline & $n$ (row \%) & $n($ row \%) & $n$ (column \%) & \\
\hline Age (years) & & & & 0.126 \\
\hline $16-24$ years & $101(94.4)$ & $6(5.6)$ & $107(23.7)$ & \\
\hline $25-34$ years & $70(85.4)$ & $12(14.6)$ & $82(18.2)$ & \\
\hline $35-44$ years & $86(87.8)$ & $12(12.2)$ & $98(21.7)$ & \\
\hline $45-54$ years & $87(94.6)$ & $5(5.4)$ & $92(20.4)$ & \\
\hline 55 years and over & $57(89.1)$ & $7(10.9)$ & $64(14.2)$ & \\
\hline Unknown & $3(37.5)$ & $5(62.5)$ & $8(1.8)$ & \\
\hline Gender identity ${ }^{b}$ & & & & 0.091 \\
\hline Cis man & $225(87.5)$ & $32(12.5)$ & $257(57.0)$ & \\
\hline Cis woman & $159(93.0)$ & $12(7.0)$ & $171(37.9)$ & \\
\hline Trans and gender expansive & $20(90.9)$ & $2(9.1)$ & $22(4.9)$ & \\
\hline Unknown & $0(0.0)$ & $1(100.0)$ & $1(0.2)$ & \\
\hline Indigenous identityc & & & & 0.164 \\
\hline Indigenous & $150(87.2)$ & $22(12.8)$ & $172(38.1)$ & \\
\hline Non-Indigenous & $216(91.9)$ & $19(8.1)$ & $235(52.1)$ & \\
\hline Unknown & $38(86.4)$ & $6(13.6)$ & $44(9.8)$ & \\
\hline Health region & & & & 0.683 \\
\hline Fraser & $86(89.6)$ & $10(10.4)$ & $96(21.3)$ & \\
\hline Interior & $106(89.1)$ & $13(10.9)$ & $119(26.4)$ & \\
\hline Island & $81(86.2)$ & $13(13.8)$ & $94(20.8)$ & \\
\hline Northern & $36(92.3)$ & $3(7.7)$ & $39(8.6)$ & \\
\hline Vancouver Coastal & $95(92.2)$ & $8(7.8)$ & $103(22.8)$ & \\
\hline Housing status & & & & $<0.01$ \\
\hline Private/Alone & $40(71.4)$ & $16(28.6)$ & $56(12.4)$ & \\
\hline Private/With Other(s) & $107(93.0)$ & $8(7.0)$ & $115(25.5)$ & \\
\hline Supportive/Unstable Housing & $193(92.8)$ & $15(7.2)$ & $208(46.1)$ & \\
\hline Homeless & $53(89.8)$ & $6(10.2)$ & $59(13.1)$ & \\
\hline Unknown & $11(84.6)$ & $2(15.4)$ & $13(2.9)$ & \\
\hline Employment & & & & 0.029 \\
\hline Yes & $126(85.1)$ & $22(14.9)$ & $148(32.8)$ & \\
\hline No & $264(92.0)$ & $23(8.0)$ & $287(63.6)$ & \\
\hline Unknown & $14(87.5)$ & $2(12.5)$ & $16(3.5)$ & \\
\hline Cellphone possession & & & & 0.027 \\
\hline
\end{tabular}




\begin{tabular}{|c|c|c|c|c|}
\hline Yes & $269(91.8)$ & $24(8.2)$ & $293(65.0)$ & \\
\hline No & $118(84.3)$ & $22(15.7)$ & $140(31.0)$ & \\
\hline Unknown & $17(94.4)$ & $1(5.6)$ & $18(4.0)$ & \\
\hline Previous GSDOA awareness & & & & 0.019 \\
\hline Yes & $205(92.8)$ & $16(7.2)$ & $221(49.0)$ & \\
\hline No & $173(85.2)$ & $30(14.8)$ & $203(45.0)$ & \\
\hline Unknown & $26(96.3)$ & $1(3.7)$ & $27(6.0)$ & \\
\hline Complete knowledge of whom the GSDOA protects ${ }^{d}$ & & & & 0.116 \\
\hline Yes & $106(95.5)$ & $5(4.5)$ & $111(24.6)$ & \\
\hline No & $99(90.0)$ & $11(10.0)$ & $110(24.4)$ & \\
\hline Unaware & $173(85.2)$ & $30(14.8)$ & $203(45.0)$ & \\
\hline Unknown & $26(96.3)$ & $1(3.7)$ & $27(6.0)$ & \\
\hline Complete knowledge of when the GSDOA protects ${ }^{\mathrm{e}}$ & & & & 0.646 \\
\hline Yes & $71(94.7)$ & $4(5.3)$ & $75(16.6)$ & \\
\hline No & $134(91.8)$ & $12(8.2)$ & $146(32.4)$ & \\
\hline Unaware & $173(85.2)$ & $30(14.8)$ & $203(45.0)$ & \\
\hline Unknown & $26(96.3)$ & $1(3.7)$ & $27(6.0)$ & \\
\hline Perceived risk of experiencing an overdose (last 6 months) & & & & 0.721 \\
\hline Never & $192(90.6)$ & $20(9.4)$ & $212(47.0)$ & \\
\hline Ever & $204(89.1)$ & $25(10.9)$ & $229(50.8)$ & \\
\hline Unknown & $8(80.0)$ & $2(20.0)$ & $10(2.2)$ & \\
\hline Perceived risk of witnessing an overdose (last 6 months) & & & & 0.292 \\
\hline Never & $45(84.9)$ & $8(15.1)$ & $53(11.8)$ & \\
\hline Ever & $348(90.6)$ & $36(9.4)$ & $384(85.1)$ & \\
\hline Unknown & $11(78.6)$ & $3(21.4)$ & $14(3.1)$ & \\
\hline Opioid use (last 6 months) & & & & 0.999 \\
\hline Yes & $224(89.2)$ & $27(10.8)$ & $251(55.7)$ & \\
\hline No & $141(89.8)$ & $16(10.2)$ & $157(34.8)$ & \\
\hline Unknown & $39(90.7)$ & $4(9.3)$ & $43(9.5)$ & \\
\hline Opioid overdose (last 6 months) e & & & & 0.854 \\
\hline Yes & $73(90.1)$ & $8(9.9)$ & $81(18.0)$ & \\
\hline No & $307(90.8)$ & $31(9.2)$ & $338(74.9)$ & \\
\hline Unknown & $24(75.0)$ & $8(25.0)$ & $32(7.1)$ & \\
\hline Stimulant overdose (last 6 months) & & & & 0.066 \\
\hline Yes & $58(84.1)$ & $11(15.9)$ & $69(15.3)$ & \\
\hline No & $321(92.0)$ & $28(8.0)$ & $349(77.4)$ & \\
\hline Unknown & $25(75.8)$ & $8(24.2)$ & $33(7.3)$ & \\
\hline
\end{tabular}




\begin{tabular}{|c|c|c|c|c|}
\hline Yes & $233(90.3)$ & $25(9.7)$ & $258(57.2)$ & \\
\hline No & $133(92.4)$ & $11(7.6)$ & $144(31.9)$ & \\
\hline Unknown & $38(77.6)$ & $11(22.4)$ & $49(10.9)$ & \\
\hline Stimulant overdose witnessed (last 6 months) & & & & 0.675 \\
\hline Yes & $159(90.9)$ & $16(9.1)$ & $175(38.8)$ & \\
\hline No & $204(89.1)$ & $25(10.9)$ & $229(50.8)$ & \\
\hline Unknown & $41(87.2)$ & 6 (12.8) & 47 (10.4) & \\
\hline
\end{tabular}

${ }^{a}$ Chi square test exclude participants with unknown independent variables

b "Trans and gender expansive" is shown but is not included in the chi square test due to small sample size

${ }^{\mathrm{c}}$ The authors recognize that Indigenous identity is often a proxy for factors associated with colonialism including intergenerational trauma, systemic racism, criminalization and discrimination.

d "Unaware" is shown but is not included in the chi square test

e "Didn't use opioids" is shown but is not included in the chi square test

\section{Table 3}

Estimated odds ratios (OR) and adjusted odds ratios (AOR) for predictors of intention to call 911 at a future overdose among participants. 


\section{Calling 911 at an OD event ${ }^{\mathrm{a}}$}

\begin{tabular}{|c|c|c|c|c|c|c|}
\hline \multirow[t]{3}{*}{ Variables } & Bivariate & \multirow{3}{*}{$\begin{array}{l}\text { Block } 1 \\
\text { (Demographics) } \\
\text { AOR }(95 \% \mathrm{Cl})\end{array}$} & \multirow{3}{*}{$\begin{array}{l}\begin{array}{l}\text { Block } 2 \\
\text { (Indigenous } \\
\text { Identity) }\end{array} \\
\text { AOR }(95 \% \mathrm{Cl})\end{array}$} & \multirow{3}{*}{$\begin{array}{l}\text { Block } 3 \\
\text { (SES) } \\
\text { AOR }(95 \% \\
\text { Cl) }\end{array}$} & \multirow{2}{*}{$\begin{array}{l}\text { Block } 4 \\
\text { (OD } \\
\text { Response) }\end{array}$} & \multirow{3}{*}{$\begin{array}{l}\text { Block } 5 \text { (OD } \\
\text { Characteristics) } \\
\text { AOR }(95 \% \mathrm{Cl})\end{array}$} \\
\hline & OR (95\% Cl) & & & & & \\
\hline & & & & & $\begin{array}{l}\mathrm{AOR}(95 \% \\
\mathrm{Cl})\end{array}$ & \\
\hline
\end{tabular}

\section{Demographic}

Characteristics

\section{Age (years)}

$16-24$

$25-34$

-

$35-44$

$0.35(0.09$,

1.40)

$-$

$45-54$

$\begin{array}{ll}0.34(0.09, & 0.43(0.11 \\ 1.35) & 1.74)\end{array}$

$0.41(0.10$,

1.70)

$-$

$45-54$

$0.71(0.15, \quad 0.88(0.19$

3.28)

4.13)

$0.40(0.10,1.66)$

$-$

$55+$

$0.24(0.06, \quad 0.30(0.07$,

1.03)

1.32)

$0.41(0.10,1.65)$

$0.35(0.08$,

$1.57)$

$0.28(0.06$, 1.31)

$\begin{array}{ll}- & - \\ 0.28(0.06, & 0.20(0.04,0.98) \text { * } \\ 1.31) & \\ 0.32(0.07, & 0.24(0.05,1.18) \\ 1.47) & \\ 0.81(0.15, & 0.55(0.10,3.07) \\ 4.29) & \\ 0.25(0.05, & 0.17(0.03,0.90) \text { * } \\ 1.25) & \end{array}$

Gender

Cis man

Cis woman

- $\quad-$

$\begin{array}{ll}2.90(1.15, & 2.59(1.01 \\ 7.35) * & 6.68) *\end{array}$

$3.00(1.15,7.83)$ * $3.05(1.14$,

$-$

$3.24(1.19, \quad 3.37(1.19,9.50)$ * $7.35)$ * 6.68$)$ * $8.15)$ *

$8.84)$ *

Indigenous Identity ${ }^{b}$

Non-indigenous

-
$0.46(0.21$,
$1.01)$

$0.38(0.17,0.85)$ *

$-$

Indigenous

1.01)

$0.43(0.18$

1.00)

$0.48(0.20, \quad 0.64(0.25,1.64)$ 1.15)

\section{SES Factors}

Housing Status

Private - Alone

Private - With others

$4.85(1.37$,

$17.21)$ *

\begin{tabular}{ll} 
& $17.21)^{\star}$ \\
Supportive/Unstable & $3.17(1.18$, \\
Housing & $8.51) \star$ \\
\hline Homeless & $2.04(0.61$, \\
& $6.81)$
\end{tabular}

Employment Status

Not employed

Employed

$0.65(0.30$

1.43)

\begin{tabular}{|c|c|c|}
\hline- & - & - \\
\hline $\begin{array}{l}3.90(1.01 \\
15.03) *\end{array}$ & $\begin{array}{l}3.65(0.94 \\
14.26)\end{array}$ & $\underset{*}{4.96}(1.21,20.29)$ \\
\hline $\begin{array}{l}3.40(1.18 \\
9.78) *\end{array}$ & $\begin{array}{l}3.56(1.20 \\
10.64) *\end{array}$ & ${ }_{*}^{3.96}(1.31,11.98)$ \\
\hline $\begin{array}{l}1.91(0.51, \\
7.16)\end{array}$ & $\begin{array}{l}2.08(0.53, \\
8.16)\end{array}$ & $2.39(0.58,9.82)$ \\
\hline
\end{tabular}

\section{Overdose Response \\ Resources}

Previous awareness

of GSDOA

Unaware

$\begin{array}{lll}- & - & - \\ 0.52(0.21, & 0.51(0.20, & 0.46(0.18,1.18) \\ 1.26) & 1.28)\end{array}$

$\begin{array}{ll}0.52(0.21, & 0.51 \\ 1.26) & 1.28)\end{array}(0.20, \quad 0.46(0.18,1.18)$ 


\section{Overdose}

Characteristics

\section{Stimulant $O D$}

\begin{tabular}{|c|c|c|c|c|c|}
\hline No & - & & & & - \\
\hline Yes & $\begin{array}{l}0.36(0.15 \\
0.81)^{\star}\end{array}$ & & & & $0.24(0.09,0.65)$ \\
\hline$L R$ Pseudo- $R^{2}$ & 0.054 & 0.083 & 0.123 & 0.166 & 0.206 \\
\hline Pseudo- $R^{2}$ change & 0.054 & 0.029 * & 0.040 & $0.043 * *$ & 0.040 ** \\
\hline
\end{tabular}

Note: $\mathrm{SES}=$ socioeconomic status, $\mathrm{OD}=$ overdose. Reference categories are denoted by $-.{ }^{\star} \mathrm{p}<0.05,{ }^{*} \mathrm{p}<0.01$

a Final model size $\mathrm{N}=327$ after excluding individuals with "unknown" responses for all variables

${ }^{b}$ The authors recognize that Indigenous identity is often a proxy for factors associated with colonialism including intergenerational trauma, systemic racism, criminalization and discrimination

Prior awareness of the GSDOA was determined by asking participants if they were aware of the GSDOA before the definition of the Act was provided. To evaluate understanding of the GSDOA, a set of questions were included that had been used previously in Mehta et al. [33]. Briefly, hypothetical overdose scenarios were outlined and participants were asked true or false questions to assess their knowledge of when and to whom protection is offered under the GSDOA. Knowledge was considered "complete" if all questions were answered correctly and "incomplete" if otherwise (See Additional File 1).

To assess perceived risks of experiencing or witnessing an overdose, respondents were asked to rate the degree to which they felt at risk of these events in the previous 6 months using a Likert-type scale. Possible responses were "never", "rarely", "sometimes", "often" or "all the time" which was dichotomized as "never" and "ever". Additional collected variables on substance use and overdose experience in the last 6 months included using opioids (yes, no, prefer not to say), overdosing on opioids (yes, no, don't know, prefer not to say), witnessing an opioid overdose (yes, no, don't know, prefer not to say), overdosing on stimulants (yes, no, don't know, prefer not to say) and witnessing a stimulant overdose (yes, no, don't know, prefer not to say).

\section{Data Analysis}

All analyses were conducted using R version 4.0.2 [46]. Frequency distributions and bivariate analyses with chi-square tests of independence were conducted to describe characteristics of participants and to explore relationships between intention to call 9-1-1 and the explanatory variables.

For multivariable analysis, candidate variables were separated into relevant categories, or blocks, that were organized by linking conceptual similarities through a concept map (See Supplementary Figure 1, Additional File 2). Notably, Indigeneity was separated from other demographic characteristics because it acts as a proxy for a number of other factors relating to colonialism as described above. Hierarchical logistic regression was then used to estimate the association of these blocks and their variables with intention to call 9-1-1 [47]. The final model was entered block by block in five steps:

1. Demographic characteristics except for Indigeneity (age, gender, health region)

2. Indigeneity (identifying as First Nations, Métis and/or Inuit)

3. Socioeconomic status characteristics (housing status, employment status)

4. Overdose response resources (cellphone possession, prior GSDOA awareness, complete understanding of the GSDOA)

5. Overdose characteristics (perceived risk of overdose, perceived risk of witnessing an overdose, stimulant overdose experienced, stimulant overdose witnessed, opioid overdose experienced, opioid overdose witnessed) 
To build the model within each block, bivariate logistic regression of each explanatory variable with the outcome variable was completed and variables with $\mathrm{p}$ value $<0.25$ were considered for selection $[48,49]$. Variables were then selected through a backwards selection approach based on minimizing the value of Akaike's information criteria (AIC) [50]. Conceptually important variables were retained in the model (i.e. age). The final selected model included: age, gender, Indigenous identity, housing status, employment status, previous awareness of the GSDOA and having experienced a stimulant overdose in the past 6 months. To illustrate the relative contribution of each block to model fit, likelihood ratio $\mathrm{R}^{2}$ was calculated after incorporating each additional block [51]. Models were also compared using the Likelihood Ratio Test with each model being compared to the model generated in the previous step [48]. The theory of planned behaviour was used as a conceptual framework to inform interpretation and discussion of results [52]. Briefly, the theory of planned behaviour posits that attitudes toward a behaviour, subjective norms and perceived behavioural controls influence the formation of a behavioral intention and this can be used to predict or understand the context of certain behaviours which, in our current study, is calling 9-1-1 for an overdose.

\section{Missing data}

Complete case analysis (CCA) was used for this study. This resulted in the exclusion of individuals with missing, "prefer not to say" or "don't know" responses which were categorized as "unknown" (Figure 2). In total, 153 (33.7\%) observations were removed from the analysis and a total of 327 responses were used for the multivariable model. The model was rerun in sensitivity analyses with multiple imputation [53]. Briefly, a parallel analysis using ten imputed datasets each generated by ten cycles of multiple imputation by chained equation (MICE) was conducted [54]. Results were verified by comparing the imputed model to the unimputed model and there were no significant differences in the conclusions, confirming confidence in the results of the CCA.

\section{Results}

\section{Demographic characteristics of study participants}

A total of 493 participants completed the GSDOA survey (Figure 2). Demographic characteristics are presented in Table 1 stratified by health region. Participants were evenly distributed across health regions except for a smaller proportion from the Northern Health region $(9.3 \%)$ due to population rurality and remoteness. Almost a quarter $(23.4 \%)$ of participants who reported their age were in the youth age group (16 - 24 years), 61.8\% were between 25 and 54 years old, and $14.7 \%$ were 55 years and over. Among participants who reported gender identity, the majority were cis men (57.7\%) followed by cis women (37.6\%) and trans and gender expansive people (4.7\%). Of those who responded to the question on Indigenous identity, a total of $55.8 \%$ identified as non-Indigenous, $29.7 \%$ identified as First Nations, $13.8 \%$ as Métis and $0.7 \%$ as Inuit.

Table 2 presents the distribution of the study variables stratified by intention to call 9-1-1 at an overdose event $(n=451)$ with most $(89.6 \%)$ reporting that they would call 9-1-1. Youth (16- 24 years) made up the largest group in this sample (23.7\%) and the majority identified as cis men (57.0\%). Furthermore, a large portion of this sample identified as non-Indigenous (52.1\%), lived in supportive/unstable housing (46.1\%), were unemployed (63.6\%) and owned a cellphone (65.0\%). Approximately half (49.0\%) of the respondents had previously heard of the GSDOA and, of those, about half (50.2\%) had complete knowledge of who is protected from charges for simple possession of a controlled substance under the GSDOA. Of those who were aware of the Act, a third (33.9\%) had complete knowledge of when protection is offered under the GSDOA. Over the prior 6 months, $50.8 \%$ of respondents felt at some risk of experiencing an overdose and $85.1 \%$ felt at some risk of witnessing an overdose. In the last 6 months, over half reported using opioids (55.7\%), 18.0\% had experienced an opioid overdose, and $15.3 \%$ had experienced a stimulant overdose. The majority of participants had witnessed an opioid overdose (57.2\%).

Willingness to call 9-1-1 was reported by a higher proportion of participants who were unemployed (92.0\%) compared to employed (85.1\%), participants who owned a cellphone (91.8\%) compared to those who did not (84.3\%), and participants who were previously aware of the GSDOA (92.8\%) compared to those who were unaware (85.2\%). Willingness to call 9-1-1 was greater among respondents living in private housing with others (93.0\%), living in supportive/unstable housing (92.8\%) and persons experiencing homelessness $(89.8 \%)$ compared to respondents who lived alone in private housing $(71.4 \%)($ all $p<0.05)$.

\section{Factors associated with an intention to call 9-1-1 at an overdose event}


Unadjusted bivariate and adjusted odds ratios from multivariable models that estimate the likelihood of intention to call 9-1-1 at an overdose event are shown in Table 3. Age was considered conceptually important and was therefore retained in the model. Models were constructed hierarchically to assess the influence of demographic characteristics, Indigeneity, socioeconomic status (SES) factors, overdose response resources and overdose characteristics on intention to call 9-1-1 at an overdose event. Demographic characteristics were not significantly associated with intention to call 9-1-1 $\left(c^{2}=10.25, p=0.68\right)$. Nevertheless, cis women were found to have more than twice the odds of intending to call 9-1-1 for an overdose compared to cis men ( $\mathrm{AOR}=2.59$ [95\% $\mathrm{Cl} 1.01,6.68])$ after adjusting for age. The addition of Indigeneity significantly improved the model fit ( $c^{2}=5.58, p=0.018$ ) and persons who identified as Indigenous had significantly lower odds of intending to call 9-1-1 in the second hierarchical model $(\mathrm{AOR}=0.38[95 \% \mathrm{Cl} 0.17,0.85])$ after adjusting for age and gender. Further adding SES factors did not significantly improve the model fit in terms of predicting intention to call 9-1-1 $\left(c^{2}=7.74, p=0.102\right)$. However, results indicated that respondents in supportive/unstable housing (AOR $=3.40$ $[95 \% \mathrm{Cl} 1.18,9.78])$ and persons living with others in private housing ( $\mathrm{AOR}=3.90$ [95\% $\mathrm{Cl} 1.01,15.03]$ ) had elevated odds of being willing to call 9-1-1 at an overdose event after adjusting for age, gender and Indigeneity. The addition of overdose response resources further improved model fit $\left(c^{2}=8.20, p<0.01\right)$. Persons who reported prior awareness of the GSDOA had over three time the odds of being willing to call 9-1-1 (AOR $=3.52$ [95\% $\mathrm{Cl} 1.42,8.69])$ after adjusting for age, gender, Indigeneity, housing status and employment status. Including overdose characteristics significantly improved the fit of the model $\left(c^{2}=7.60, p<0.01\right)$. Participants who had experienced a stimulant overdose in the past 6 months had significantly lower odds of intention to call 9-1-1 at an overdose event $(A O R=0.24[95 \% \mathrm{Cl} 0.09,0.65])$ after adjusting for age, gender, Indigeneity, housing status, employment status and previous GSDOA awareness.

To address missing data, a multivariable model was built containing the same variables but using pooled imputed datasets generated by multiple imputation by chained equation ( $N=493)$ (See Supplementary Table 1, Additional File 2). Though the strength of association changed for some explanatory variables, the directions of the associations of interest were consistent with unimputed results from Table 3 .

\section{Discussion}

About ten percent of the sample reported that the GSDOA did not affect their intent to call 9-1-1 at a future overdose event and a number of characteristics have been found to be associated with this intent. We found higher odds of intention to call 9-1-1 among cis women, non-Indigenous respondents, participants living in supportive, unstable or private housing with others compared to private housing alone, persons with prior awareness of the GSDOA, and participants who had not experienced a stimulant overdose over the last 6 months. Importantly, demographic factors, apart from Indigeneity, and SES factors did not significantly improve the model fit. Overdose response resources and overdose characteristics each accounted for a significant portion of the variation in the outcome variable over and above the factors included before them. This suggests that, in our model, demographic and SES factors had a relatively less important role in predicting intention to call 9-1-1 at an overdose compared to Indigeneity and overdose-related factors.

Previous studies have assessed factors associated with calling 9-1-1 at an overdose among samples of people with variable knowledge of drug related Good Samaritan laws, which have been implemented in many states throughout the US[13-15, 55, 56]. Although our study included a substantial proportion of youth (aged 16-24), a population that has previously been identified as reticent to call 9-1-1 due to fear of criminalization and mistrust of police[4, 21, 57, 58], we did not find that intent to call 9-1-1 differed by this age group (Block 1). Future research should investigate the potential age-related dynamics to intention to call 9-1-1 at overdose events given prior research in this area. In addition, we found that cis women were more likely to express intention to call 9-1-1 at a future overdose event. This broadly corroborates previous research on sex and gender that found a higher likelihood of 9-1-1 being called when female bystanders were present $[14,15]$. Psychology research has indicated that women achieve higher scores in empathy and help-seeking and that these qualities are more likely to manifest in others when women are present[59-61]. Furthermore, norms surrounding masculinity that reject vulnerability and seeking out care may contribute to reduced odds of calling 911 among cis-men[62,63]. Taken together with our findings, further research is necessary to elucidate the role of gender on seeking help at overdose events.

We also found decreased likelihood of calling 9-1-1 among people who have overdosed on stimulants in the last 6 months. Ambrose et al.[14]similarly found that the odds of calling 9-1-1 are lower if persons had a previous stimulant overdose. The effects of using stimulants are different from those of opioids, and may impact help seeking and interactions with first responders who can have stigmatizing perceptions of people who use stimulants[64, 65]. Consequently, compared to those who use opioids, people who use

Page 12/21 
stimulants have increased odds of being incarcerated, and are more likely to experience an overnight hospital stay [66, 67]. Therefore, people who use stimulants may experience additional risk of harm at overdose events, which may affect attitudes around calling 9-11 at future overdose events. More research is needed to confirm this. In addition, our findings could also be reflective of a lower perceived need for naloxone, calling 9-1-1 and the GSDOA among people who use stimulants compared to people who use only opioids.

Our finding that those living in a private residence alone had lower odds of intention to call 9-1-1 compared to persons living in private housing with others and persons in supportive or unstable housingis supported by past research. Specifically, a study in New York City, US and two studies conducted in BC found decreased odds of calling 9-1-1 for overdoses occurring in private residences and a higher likelihood of 9-1-1 being called if an overdose was witnessed in a public setting (e.g. on the street)[13, 14, 26]. Additionally, a recent Vancouver study found lower odds of calling 9-1-1 among persons living in SROs compared to other private residences[56]. Bystanders to overdose in private residences may be concerned about lacking anonymity or losing housing as a result of drug use being discovered $[68,69]$. This could be particularly relevant for people who live alone as the presence of emergency personnel at their residence could be directly linked to them as would potential repercussions such as loss of housing or eviction.

Respondents who were previously aware of the GSDOA had a higher likelihood of intention to call 9-1-1 at future overdose events. Past research has provided evidence for an association between awareness of the GSDOA and intent to call 9-1-1[26, 55, 70-72]. Since all respondents were educated about the GSDOA, our finding suggests that reinforcing education of the Act can increase intention to call 9-1-1. Jakubowski et al.[26]had similar results with people who received repeated Good Samaritan law instruction at 3-, 6- and 12month follow-up points and saw correct knowledge of the Good Samaritan law increase each time. This reinforces the importance of expanding GSDOA awareness and knowledge as well as continuing targeted dissemination of the Act.

Our findings indicated that participants who identified as Indigenous had lower odds of intending to call 9-1-1. The addition of subsequent blocks to the hierarchical model reduced this effect to the point where it lacked statistical significance, suggesting that there may have been other factors contributing to this association. Indigenous people are racially profiled and mistreated by police and health care professionals in Canada[73-75]. Compared to non-Indigenous people, Indigenous people are disproportinately incarcerated, making up over $25 \%$ of the correctional facility population while only representing $4.5 \%$ of the Canadian population[76, 77]. This is largely a result of the ongoing impacts of colonization, including anti-Indigenous discrimination. Indigenous people contend with precarious encounters with law enforcement, characterized by risks of violence and discrimination, which contribute to a fear or reduced willingness to contact and interact with the police[78]. Our study may reflect these barriers to calling 9-1-1 among Indigenous respondents that are not addressed by the GSDOA [42-45]. The 2020 report In Plain Sight: Addressing Indigenous-Specific Racism and Discrimination in B.C. Health Care contains policy recommendations meant to address interpersonal and institutional anti-Indigenous racism in health setting[79]. This includes developing an Anti-Racism Act and amending the Health Professions Act, Hospitals Act, and Health Authorities Act to set standards and expectations of anti-racism and Indigenous cultural safety for employees in the health care system including policymakers, clinicians and paramedics. The GSDOA cannot be separated from the sociopolitical context in which it operates as forces such as anti-Indigenous racism certainly have an impact on how PWUD experience the GSDOA as well as their interactions with first responders and hospital personnel. Policies addressing racism and promoting equitable access to EMS are paramount for the effectiveness of policies such as the GSDOA. To further improve implementation of the GSDOA, efforts should focus on constant and reflective relationship-building efforts between law enforcement and populations who may be distrustful of police.

To better connect our results to behaviour intentions and identify areas that may respond to interventions, we drew on the theory of planned behaviour as a conceptual framework[52]. According to the theory of planned behaviour, attitudes toward a behaviour, subjective norms and perceived behavioural controls combine to form a behavioral intention (i.e., intention to call 9-1-1 at an overdose event). Indigenous, Black and People of Colour have and continue to report negative interactions with police officers and this has led to attitudes of distrust towards police among these groups[73-75, 80]. Furthermore, people experiencing homelessness and PWUD continue to be criminalized by police[17, 21]. This may be compounded by the subjective norm that one should not call or involve police as this may be perceived as "ratting" on others and potentially subject others to harms associated with police involvement[17, 81]. Masculinity is another subjective norm to consider as this has been shown to lower odds of calling 9-1-1 in men[62, 63]. Though none of the associated factors in our model can be readily described as a perceived behavioural control, one important control to consider from outside the model is cellphone possession. Specifically, over a third of respondents did not have a cellphone and therefore had a potential added barrier to calling 9-1-1 at future overdose events. Furthermore, willingness to call 9-1-1 differed 
significantly between cellphone owners and those who did not own a cellphone. Altogether, the application of the theory of planned behaviour to our findings highlights that one's intention to call 9-1-1 at overdose events is complicated by many overlapping influences that operate on both the individual- and environmental-level. Additional qualitative and quantitative research is required to capture the many unique scenarios and circumstances that impact overdose bystanders' decision-making process.

Despite the sample indicating a high level of intent to call after receiving education about the GSDOA, about ten percent of the sample indicated they would not call. The disparities in intention to call 9-1-1 highlight the need for several interventions to support the aims of the GSDOA. First, the protections of the GSDOA should be expanded to protect bystanders who may fear losing housing or employment if they call 9-1-1. Many PWUD are engaged in criminalized work (e.g. sex work, drug dealing) and this should be taken into account when expanding GSDOA protections $[82,83]$. Further, instances of police discretion should be minimized to limit inconsistencies in how people at overdose events experience the GSDOA [29, 84]. De jure decriminalization policies that are developed in collaboration with PWLLE are also needed to address the limitations of the narrow form of decriminalization that is the GSDOA. Calls and recommendations from the In PlainSight report[79]should be followed to improve access to care and interactions with first responders for Indigenous, Black and People of Colour. Considering the studies in BC that have highlighted low to moderate levels of GSDOA awareness and understanding among PWUD and police officers[28, 29, 33], continued knowledge dissemination efforts, especially to subgroups with lower GSDOA awareness and understanding, is warranted and necessary to improve the implementation of the GSDOA.

The findings of this study have several limitations. Respondents were recruited by convenience sampling and this research relied largely on respondents at THN sites. Although the study used THN and Foundry sites in all the health regions of BC, most sites were in urban locations and may not therefore adequately capture the perceptions and experiences of people residing in rural areas. Indigenous identity was assessed, however race and ethnicity was not assessed for those who identified as non-Indigenous. Future studies should assess potential differences in willingness to call 9-1-1 and interactions with police between Indigenous, Black and People of Color and non-racialized people. Though the GSDOA has been implemented on the federal level in Canada, this study exclusively took place in BC and may not be applicable to other provinces or countries with similar drug related Good Samaritan laws, such as the USA. These limitations altogether impact the generalizability of the study to all people who may witness an overdose. Additionally, we cannot determine the temporality between the explanatory and outcome variables due to the cross-sectional design of the study. Due to the self-reported nature of our survey, we also cannot rule out certain respondent biases (e.g. confirmation bias, recall bias, social desirability bias). Altogether, the level of intent to call 9-1-1 may be overestimated, especially considering that most participants were recruited at THN sites and those with THN training and experience administering naloxone are more likely to call 9-11 for an overdose [56]. Sensitivity analysis was completed using imputed datasets and, while the direction of the main associations of interest remained unchanged, associations of the outcome variable with other covariates differed. This limits our ability to make conclusions about the magnitude of the relationships given that they differ across the imputed and unimputed models.

\section{Conclusions}

This study uniquely assessed the level of intent and factors associated with intent to call 9-1-1 at future overdose events across 19 THN program sites in $\mathrm{BC}$ among people at risk of witnessing an overdose and who were educated of the GSDOA. Our findings show that about $10 \%$ of the sample indicated that the GSDOA did not affect their intent to call 9-1-1 at a future overdose event. Our recommendations, informed by the theory of planned behaviour, include public education of the GSDOA, the expansion of the GSDOA's legal protections, implementation of broader decriminalization and the development of anti-racist policy for first responders in order to mitigate barriers to calling 9-1-1 for an overdose and ultimately reduce overdose deaths.

\section{Declarations}

\section{Ethics approval and consent to participate}

The study was approved by the University of British Columbia Office of Behavioural Rsearch Ethics (\#H19-01842).

\section{Consent for publication}

All authors gave final approval to the publication of this manuscript, and all participants gave consent to participate in the study. 


\section{Availability of data and materials}

The datasets analyzed during the current study are available from the corresponding author on reasonable request.

\section{Competing interests}

The authors declare that they have no competing interests.

\section{Funding}

Author JAB is principal investigator for the Good Samaritan Drug Overdose Act evaluation, a project funded by the British Columbia Ministry of Health. The funders had no input into the study design, analysis or manuscript development.

\section{Authors' contributions}

BK: designed the analysis, interpreted and analysed the data, drafted the manuscript; JX: conceptualized and designed the study, provided contributions and critically revised the manuscript; MF: designed the analysis, interpreted and analyzed the data, provided contributions and critically revised the manuscript; HP: provided contributions and critically revised the manuscript; SM: critically revised the manuscript; AS: provided contributions and critically revised the manuscript; TG: critically revised the manuscript; RV: critically revised the manuscript; JAB: conceptualized the study, provided contributions and critically revised the manuscript. All authors read and approved the final manuscript.

\section{Acknowledgements}

The authors are grateful to participants, harm reduction sites staff, Foundry staff and volunteers, and regional harm reduction coordinators for their support and participation in the study. The authors also thank Professionals for Ethical Engagement of Peers and members of the Peer2Peer Project for their insights. We respectfully acknowledge that we live and work on the unceded traditional territories of the Coast Salish Peoples, including the territories of x məӨk əýəm (Musqueam), Skwxwú7mesh (Squamish), and səlililw əta (Tsleil-Waututh) Nations, and that the Good Samaritan Drug Overdose Act survey was conducted across the unceded traditional territories of 198 First Nations.

\section{References}

1. Public Health Agency of Canada. Opioid- and Stimulant-related Harms in Canada [Internet]. Special Advisory Committee on the Epidemic of Opioid Overdoses; 2021 [cited 2021 July 14]. Available from: https://health-infobase.canada.ca/substance-relatedharms/opioids-stimulants.

2. Mattson CL, Tanz LJ, Quinn K, Kariisa M, Patel P, Davis NL. Trends and Geographic Patterns in Drug and Synthetic Opioid Overdose Deaths - United States, 2013-2019. MMWR Morb Mortal Wkly Rep. 2021;70(6):202-

7.https://doi.org/10.15585/mmwr.mm7006a4.

3. Crabtree A, Lostchuck E, Chong M, Shapiro A, Slaunwhite A. Toxicology and prescribed medication histories among people experiencing fatal illicit drug overdose in British Columbia, Canada. CMAJ. 2020;192(34):E967 -

E72.https://doi.org/10.1503/cmaj.200191.

4. British Columbia Coroners Service. Illicit Drug Toxicity Deaths in BC January 1, 2011 - May 31, 2021 [Internet]. Ministry of Public Safety \& Solicitor General; 2021 [cited 2021 July 14]. Available from:https://www2.gov.bc.ca/assets/gov/birth-adoption-deathmarriage-and-divorce/deaths/coroners-service/statistical/illicit-drug.pdf.

5. BC Ministry of Health. Provincial health officer declares public health emergency [Internet]. 2016 [cited 2021 July 18]. Available from:https://news.gov.bc.ca/releases/2016hlth0026-000568.

6. Foldes FF, Duncalf D, Kuwabara S. The respiratory, circulatory, and narcotic antagonistic effects of nalorphine, levallorphan, and naloxone in anaesthetized subjects. Can Anaes Soc J. 1969;16(2):151-61.https://doi.org/10.1007/BF03005795.

Page $15 / 21$ 
7. Young S, Williams S, Otterstatter M, Lee J, Buxton J. Lessons learned from ramping up a Canadian Take Home Naloxone programme during a public health emergency: a mixed-methods study. BMJ Open.

2019;9:e030046.https://doi.org/10.1136/bmjopen-2019-030046.

8. BC Centre for Disease Control. BC Centre for Disease Control and Provincial Health Officer Position Statement - Observed Consumption Services [Internet]. BC Centre for Disease Control; 2019 [cited 2021 July 16]. Available from:http://www.bccdc.ca/resourcegallery/Documents/Statistics\%20and\%20Research/Statistics\%20and\%20Reports/Overdose/Final_OCSStatement_June2019.pdf.

9. BCCDC Harm Reduction Services. THN in BC Infograph - July 2021 [Internet]. 2021 [cited 2021 Aug 15]. Available from:https://towardtheheart.com/thn-in-bc-infograph.

10. Boyer EW. Management of Opioid Analgesic Overdose. N Engl J Med. 2012;367(2):14655.https://doi.org/10.1056/NEJMra1202561.

11. Clark AK, Wilder CM, Winstanley EL. A systematic review of community opioid overdose prevention and naloxone distribution programs. J Addict Med. 2014;8(3):153-63.https://doi.org/10.1097/ADM.0000000000000034.

12. Lim JK, Bratberg JP, Davis CS, Green TC, Walley AY. Prescribe to Prevent: Overdose Prevention and Naloxone Rescue Kits for Prescribers and Pharmacists. J Addict Med. 2016;10(5):300-8.https://doi.org/10.1097/ADM.0000000000000223.

13. Karamouzian M, Kuo M, Crabtree A, Buxton JA. Correlates of seeking emergency medical help in the event of an overdose in British Columbia, Canada: Findings from the Take Home Naloxone program. Int J Drug Policy. 2019;71:15763.https://doi.org/10.1016/j.drugpo.2019.01.006.

14. Ambrose G, Amlani A, Buxton JA. Predictors of seeking emergency medical help during overdose events in a provincial naloxone distribution programme: a retrospective analysis. BMJ Open. 2016;6(6):e011224.https://doi.org/10.1136/bmjopen-2016-011224.

15. Tobin KE, Davey MA, Latkin CA. Calling emergency medical services during drug overdose: an examination of individual, social and setting correlates. Addiction. 2005;100(3):397-404.https://doi.org/10.1111/j.1360-0443.2005.00975.x.

16. Canadian Community Epidemiology Network on Drug Use. CCENDU Bulletin Calling 911 in Drug Poisoning Situations [Internet]. Canadian Centre on Substance Abuse; 2017 [cited 2021 July 19]. Available from:https://www.ccsa.ca/sites/default/files/201904/CCSA-CCENDU-Calling-911-Drug-Poisoning-2017-en.pdf.

17. Latimore AD, Bergstein RS. "Caught with a body" yet protected by law? Calling 911 for opioid overdose in the context of the Good Samaritan Law. Int J Drug Policy. 2017;50:82-9.https://doi.org/10.1016/j.drugpo.2017.09.010.

18. Koester S, Mueller SR, Raville L, Langegger S, Binswanger IA. Why are some people who have received overdose education and naloxone reticent to call Emergency Medical Services in the event of overdose? Int J Drug Policy. 2017;48:11524.https://doi.org/10.1016/j.drugpo.2017.06.008.

19. Greer A, Sorge J, Sharpe K, Bear D, Macdonald S. Police Encounters and Experiences among Youths and Adults Who Use Drugs: Qualitative and Quantitative Findings of a Cross-Sectional Study in Victoria, British Columbia. Can J Criminol Crim. 2018;60(4):478-504.https://doi.org/10.3138/cjccj.2017-0044.r1.

20. Greer A, Selfridge M, Watson TM, Macdonald S, Pauly B. Young People Who Use Drugs Views Toward the Power and Authority of Police Officers. Contemp Drug Probl. 2021:1-22.https://doi.org/10.1177/00914509211058989.

21. Selfridge M, Greer A, Card KG, Macdonald S, Pauly B. "It's like super structural" - Overdose experiences of youth who use drugs and police in three non-metropolitan cities across British Columbia. Int J Drug Policy. 2020;76:102623.https://doi.org/10.1016/j.drugpo.2019.102623.

22. Vancouver Police Department. 1.6.28 Guidelines for police attending illicit drug overdoses. In Regulations and procedures manual [Internet]. 2006 [cited 2021 July 19]. Available from:https://vpd.ca/policies-strategies/vpd-regulations-procedures-manual/.

23. Mehta A, Palis H, Jennesen S, Lilley N, Slemko R, Buxton J. Change in police notification and police attendance after the BC Emergency Health Services introduced a policy to not routinely notify police of all overdose events. [Internet]. 2021 [cited 2021 July 13]. Available from:https://towardtheheart.com/assets/uploads/16291504863X5WRWTiVvSKiotWuMcsueEBkjcA039CquhDrD9.pdf.

24. Government of Canada. About the Good Samaritan Drug Overdose Act [Internet]. 2021 [cited 2021 July 15]. Available from:https://www.canada.ca/en/health-canada/services/opioids/about-good-samaritan-drug-overdose-act.html.

25. Moallef S, Hayashi K. The effectiveness of drug-related Good Samaritan laws: A review of the literature. Int J Drug Policy. 2021;90:102773.https://doi.org/10.1016/j.drugpo.2020.102773. 
26. Jakubowski A, Kunins HV, Huxley-Reicher Z, Siegler A. Knowledge of the 911 Good Samaritan Law and 911-calling behavior of overdose witnesses. Subst Abus. 2018;39(2):233-8.https://doi.org/10.1080/08897077.2017.1387213.

27. Evans TI, Hadland SE, Clark MA, Green TC, Marshall BD. Factors associated with knowledge of a Good Samaritan Law among young adults who use prescription opioids non-medically. Harm Reduct J. 2016;13(1):24.https://doi.org/10.1186/s12954-0160113-2.

28. Moallef S, DeBeck L, Milloy M, Somers J, Kerr T, Hayashi K. Knowledge of a Drug-Related Good Samaritan Law Among People Who Use Drugs, Vancouver, Canada. Health Educ Behav. 2021:1090198121999303.https://doi.org/10.1177/1090198121999303.

29. Xavier J, Greer A, Crabtree A, Ferencz S, Buxton JA. Police officers' knowledge, understanding and implementation of the Good Samaritan Drug Overdose Act in BC, Canada. Int J Drug Policy. 2021;97:103410.https://doi.org/10.1016/j.drugpo.2021.103410.

30. Atkins DN, Durrance CP, Kim Y. Good Samaritan harm reduction policy and drug overdose deaths. Health Serv Res. 2019;54(2):407-16.https://doi.org/10.1111/1475-6773.13119.

31. McClellan C, Lambdin BH, Ali MM, Mutter R, Davis CS, Wheeler E, Pemberton M, Kral AH. Opioid-overdose laws association with opioid use and overdose mortality. Addict Behav. 2018;86:90-5.https://doi.org/10.1016/j.addbeh.2018.03.014.

32. Rees DI, Sabia JJ, Argys LM, Dave D, J L. With a Little Help from My Friends: The Effects of Good Samaritan and Naloxone Access Laws on Opioid-Related Deaths. J Law Econ. 2019;62(1):1 - 27.https://doi.org/10.1086/700703.

33. Mehta A, Moustaqim-Barrette A, Papamihali K, Xavier J, Graham B, Williams S, Buxton JA. Good Samaritan Drug Overdose Act awareness among people who use drugs in British Columbia, Canada. J Community Saf Well Being. 2021;6(3):133 41.https://doi.org/10.35502/jcswb.197.

34. McNeil R, Cooper H, Small W, Kerr T. Area restrictions, risk, harm, and health care access among people who use drugs in Vancouver, Canada: A spatially oriented qualitative study. Health Place. 2015;35:708.https://doi.org/10.1016/j.healthplace.2015.07.006.

35. Paquette CE, Syvertsen JL, Pollini RA. Stigma at every turn: Health services experiences among people who inject drugs. Int J Drug Policy. 2018;57:104-10.https://doi.org/10.1016/j.drugpo.2018.04.004.

36. van Boekel LC, Brouwers EP, van Weeghel J, Garretsen HF. Stigma among health professionals towards patients with substance use disorders and its consequences for healthcare delivery: systematic review. Drug Alcohol Depend. 2013;131(1-2):2335.https://doi.org/10.1016/j.drugalcdep.2013.02.018.

37. Qualtrics. Qualtrics Core XM Survey Software [Internet]. 2020 [cited 2021 July 12]. Available from:https://www.qualtrics.com/uk/core-xm/survey-software/.

38. United Nations. Secretary-General's Report to the General Assembly A/56/180 [Internet]. 2001 [cited 2021 December 18]. Available from:https://www.youthpolicy.org/basics/2001_WPAY_Implementation_Report.pdf.

39. Strang J, Manning V, Mayet S, Titherington E, Offor L, Semmler C, Williams A. Family carers and the prevention of heroin overdose deaths: Unmet training need and overlooked intervention opportunity of resuscitation training and supply of naloxone. Drugs (Abingdon Engl). 2008;15(2):211-8.https://doi.org/10.1080/09687630701731205.

40. Mamdani Z, McKenzie S, Pauly B, Cameron F, Conway-Brown J, Edwards D, Howell A, Scott T, Seguin R, Woodrow P, Buxton JA. "Running myself ragged": stressors faced by peer workers in overdose response settings. Harm Reduct J. 2021;18(1):18.https://doi.org/10.1186/s12954-020-00449-1.

41. Bardwell G, Kerr T, Boyd J, McNeil R. Characterizing peer roles in an overdose crisis: Preferences for peer workers in overdose response programs in emergency shelters. Drug Alcohol Depend. 2018;190:6-

8.https://doi.org/10.1016/j.drugalcdep.2018.05.023.

42. Interagency Coalition on AIDS and Development. Indigenous Harm Reduction = Reducing the Harms of Colonization [Internet]. 2019 [cited 2021 September 10]. Available from:http://www.icad-cisd.com/publication/indigenous-harm-reduction-reducingharms-colonization/.

43. Kim PJ. Social Determinants of Health Inequities in Indigenous Canadians Through a Life Course Approach to Colonialism and the Residential School System. Health Equity. 2019;3(1):378-81.https://doi.org/10.1089/heq.2019.0041.

44. Wardman D, Quantz D. Harm reduction services for British Columbia's First Nation population: a qualitative inquiry into opportunities and barriers for injection drug users. Harm Reduct J. 2006;3:1-6.https://doi.org/10.1186/1477-7517-3-30.

45. Dell C, Lyons T. Harm Reduction Policies and Programs for Persons of Aboriginal Descent. In: Harm Reduction for Special Populations in Canada. Ottawa, Ontario: Canadian Centre on Substance Abuse; 2007. ch.3 p.1-20.

Page $17 / 21$ 
46. R Core Team. R: A language and environment for statistical computing. [Internet]. R Foundation for Statistical Computing; 2021 [cited 2021 July 12]. Available from:https://www.r-project.org/.

47. Kim B. Hierarchical Linear Regression. [Internet]. University of Virginia Library Research Data Services + Sciences; 2016 [cited 2021 July 20]. Available from:https://data.library.virginia.edu/hierarchical-linear-regression/.

48. Hosmer DW, Lemeshow S, Sturdivant RX. Model-Building Strategies and Methods for Logistic Regression. In: Hosmer DW, Lemeshow S, Sturdivant RX, editors. Applied Logistic Regression. 3 ed. New York: Wiley; 2013. p. 89 - 151.

49. Zhang Z. Model building strategy for logistic regression: purposeful selection. Ann Transl Med. 2016;4(6):111.https://doi.org/10.21037/atm.2016.02.15.

50. Akaike H. Akaike's information criterion. In: Lovric M, editor. International encyclopedia of statistical science. Berlin: Springer; 2011. p. 25

51. Cohen J, Cohen P, West SG, Aiken LS. Alternative Regression Models: Logistic, Poisson Regression, and the Generalized Linear Model. In: Cohen J, Cohen P, West SG, Aiken LS, editors. Applied Multiple Regression/Correlation Analysis for the Behavioral Sciences, 3 Ed. Abingdon, UK: Routledge; 2013.

52. Ajzen I. The theory of planned behaviour. Organ Behav Hum Decis Process. 1991;50(2):179-211.https://doi.org/10.1016/07495978(91)90020-T.

53. Enders CK. Applied Missing Data Analysis. New York, NY: Guilford Press; 2010.

54. Azur MJ, Stuart EA, Frangakis C, Leaf PJ. Multiple imputation by chained equations: what is it and how does it work? Int J Methods Psychiatr Res. 2011;20(1):40 - 9.https://doi.org/10.1002/mpr.329.

55. Zadoretzky C, McKnight C, Bramson H, Des Jarlais D, Phillips M, Hammer M, Cala ME. The New York 911 Good Samaritan Law and Opioid Overdose Prevention Among People Who Inject Drugs. World Med Health Policy. 2017;9(3):31840.https://doi.org/10.1002/wmh3.234.

56. Moallef S, Choi J, Milloy MJ, DeBeck K, Kerr T, Hayashi K. A drug-related Good Samaritan Law and calling emergency medical services for drug overdoses in a Canadian setting. Harm Reduct J. 2021;18(1):91.https://doi.org/10.1186/s12954-021-00537-w.

57. Representative for Children and Youth. Time to Listen: Youth Voices on Substance Use [Internet]. 2018 [cited 2021 September 21]. Available from:https://rcybc.ca/reports-and-publications/reports/reviews-and-investigations/time-to-listen-youth-voices-onsubstance-use/.

58. Chang DC, Rieb L, Nosova E, Liu Y, Kerr T, DeBeck K. Hospitalization among street-involved youth who use illicit drugs in Vancouver, Canada: a longitudinal analysis. Harm Reduct J. 2018;15(14):1-6.https://doi.org/doi:10.1186/s12954-018-0223-0.

59. George D, Carroll P, Kersnick R, Calderon K. Gender-related patterns of helping among friends. Psychol Women Q. 1998;22:685704.https://www.burmanu.ca/sites/default/files/Faculty\%20Profile\%20Information/Darren\%20George/6\%20PublicationGenderPatternsPDF.pdf.

60. Eagly A, Crowley M. Gender and helping behavior: a meta-analytic review of the social psychological literature. Psychol Bull. 1986;100:283-308.https://doi.org/10.1037/0033-2909.100.3.283.

61. Christov-Moore L, Simpson EA, Coudé G, Grigaityte K, lacoboni M, Ferrari PF. Empathy: gender effects in brain and behavior. Neurosci Biobehav Rev. 2014;46(4):604-27.https://doi.org/10.1016/j.neubiorev.2014.09.001.

62. Mahalik JR, Good GE, Englar-Carlson M. Masculinity scripts, presenting concerns, and help seeking: Implications for practice and training. Prof Psychol Res Pr. 2003;34(2):123-31.https://doi.org/10.1037/0735-7028.34.2.123.

63. Connell RW, Messerschmidt JW. Hegemonic Masculinity: Rethinking the Concept. Gend Soc. 2005;19:829 59.https://doi.org/10.1177/0891243205278639.

64. Monds LA, Cullen HJ, Kloft L, Sumampouw N, van Golde C, Harrison AW, Otgaar H. Police perceptions of eyewitness impairment due to alcohol and other drug use: a cross-cultural comparison. Police Pract Res. 2021; ahead-of-print:1 16.https://doi.org/10.1080/15614263.2021.1979397.

65. Shachar C, Wise T, Katznelson G, Campbell AL. Criminal Justice or Public Health: A Comparison of the Representation of the Crack Cocaine and Opioid Epidemics in the Media. J Health Polit Policy Law. 2021;45(2):211-

39.https://doi.org/10.1215/03616878-8004862.

66. Gjersing L, Bretteville-Jensen AL. Characteristics and risk of incarceration among hard-to-reach people who use drugs: A five-year prospective cohort study combining self-reports and registry data. Int J Drug Policy. 
2021;95:103288.https://doi.org/10.1016/j.drugpo.2021.103288.

67. Leeman RF, Sun Q, Bogart D, Beseler CL, Sofuoglu M. Comparisons of Cocaine-Only, Opioid-Only, and Users of Both Substances in the National Epidemiologic Survey on Alcohol and Related Conditions (NESARC). Subst Use Misuse. 2016;51(5):553 -

64.https://doi.org/10.3109/10826084.2015.1122063.

68. Bowles JM, Smith LR, Verdugo SR, Wagner KD, Davidson PJ. "Generally, you get 86'ed because you're a liability": An application of Integrated Threat Theory to frequently witnessed overdoses and social distancing responses. Soc Sci Med. 2020;260:113190.https://doi.org/10.1016/j.socscimed.2020.113190.

69. Tracy M, Piper TM, Ompad D, Bucciarelli A, Coffin PO, Vlahov D, Galea S. Circumstances of witnessed drug overdose in New York City: implications for intervention. Drug Alcohol Depend. 2005;79(2):181-90.https://doi.org/10.1016/j.drugalcdep.2005.01.010.

70. Watson DP, Ray B, Robison L, Huynh P, Sightes E, Walker S, Brucker K, Duwve J. Lay responder naloxone access and Good Samaritan law compliance: postcard survey results from 20 Indiana counties. Harm Reduct $J$.

2018;15(1):18.https://doi.org/10.1186/s12954-018-0226-x.

71. McLeod KE, Xavier J, Okhowat A, Williams S, Korchinski M, Young P, Papamihali K, Martin RE, Monaghan A, Sharifi N, Buxton JA. Knowledge of the Good Samaritan Drug Overdose Act and possession of a Take Home Naloxone kit among people recently released from provincial correctional facilities in British Columbia. Int J Prison Health. 2021;18(1):43 -

54.https://doi.org/10.1108/IJPH-04-2021-0033.

72. Banta-Green C, Kuszler O, Coffin P, Schoeppe J. Washington's 911 Good Samaritan Drug Overdose Law-Initial Evaluation Results [Internet]. Alcohol \& Drug Abuse Institute, University of Washington; 2011 [cited 2021 July 18]. Available from:https://adai.uw.edu/pubs/infobriefs/ADAl-IB-2011-05.pdf.

73. Palmater P. Shining light on the dark places: Addressing police racism and sexualized violence against Indigenous women and girls in the national inquiry. Can J Women Law. 2016;28(2):253-84.https://doi.org/10.3138/cjwl.28.2.253.

74. Lithopoulos S, Ruddel R. Policing isolated Aboriginal communities: Perspectives of Canadian officers. Policing. 2011;34(3):43453.https://doi.org/10.1108/13639511111157500.

75. Nettelbeck A, Smandych R. Policing Indigenous Peoples on Two Colonial Frontiers: Australia's Mounted Police and Canada's North-West Mounted Police. Aust N Z J Criminol. 2010;43(2):356-75.https://doi.org/10.1375/acri.43.2.356.

76. Government of Canada. Adult and youth correctional statistics in Canada, 2018/2019 [Internet]. Canadian Centre for Justice and Community Safety Statistics; 2020 [cited 2021 Sep 17]. Available from:https://www150.statcan.gc.ca/n1/pub/85-002x/2020001/article/00016-eng.htm.

77. The Council of Canadian Academies. Toward Peace, Harmony, and Well-Being: Policing in Indigenous Communities [Internet]. The Expert Panel on Policing in Indigenous Communities; 2019 [cited 2021 Sep 17]. Available from:https://cca-reports.ca/wpcontent/uploads/2019/04/FullReport-Toward-Peace-Harmony-and-WellBeing.pdf.

78. Cao L. Aboriginal People and Confidence in the Police. Can J Criminol Crim Justice. 2014;56(5):499 526.https://doi.org/10.3138/CJCCJ.2013.E05.

79. Turpel-Lafond ME. In Plain Sight: Addressing Indigenous-specific racism and discrimination in BC health care [Internet]. 2020 [cited 2021 Sep 17]. Available from:https://engage.gov.bc.ca/app/uploads/sites/613/2020/11/In-Plain-Sight-Full-Report.pdf.

80. British Columbia's Office of the Human Rights Commissioner. Equity is safer: Human rights considerations for policing reform in British Columbia [Internet]. 2021 [cited 2021 Sep 18]. Available from:https://bchumanrights.ca/publications/scorpa/.

81. Rudzinski K, Strike C. Resilience in the Face of Victimization: A Bourdieusian Analysis of Dealing With Harms and Hurts Among Street-Involved Individuals Who Smoke Crack Cocaine. Contemp Drug Probl. 2020;47(1):3-

28.https://doi.org/10.1177/0091450920907425.

82. DeBeck K, Shannon K, Wood E, Li K, Montaner J, Kerr T. Income generating activities of people who inject drugs. Drug Alcohol Depend. 2007;91(1):50 - 6.https://doi.org/10.1016/j.drugalcdep.2007.05.003.

83. Chettiar J, Shannon K, Wood E, Zhang R, Kerr T. Survival sex work involvement among street-involved youth who use drugs in a Canadian setting. J Public Health (Oxf). 2010;32(3):322 - 7.https://doi.org/10.1093/pubmed/fdp126.

84. van der Meulen E, Ka Hon Chu S, Butler-McPhee J. "That's why people don't call 911": Ending routine police attendance at drug overdoses. Int J Drug Policy. 2021;88:103039.https://doi.org/10.1016/j.drugpo.2020.103039.

\section{Figures}

Page 19/21 


\section{THEGOODSAMARTANDRUG OVERDOSEACT}

RECENED ROYAL ASSENT ON MAY $4^{T H}, 2017$

This enactment amends the Controlled Drugs and Substances Act to exempt persons sœeking emergency medical or law enforcement assistance for themselves or for others at an overdose from being charged for simple possession or for violation of pretrial relesse, probation order, conditional sentence, or parole related to simple posession, if the evidence in support of that offence was obtained or discovered as a result of seeking assistance or remaining at the soene. This applies to any person at the scene upon the arrival of assistance, including the person who overdosed.

\section{F YOU SUSPECT ANOVERDOSE, CAL 911}

STAY WITH THE PERSON UNT $\mathbb{1}$ HE P ARRNES

\begin{tabular}{|c|c|}
\hline $\begin{array}{l}\text { THE LAW DOESPROVIDE } \\
\text { PROTECTION FROM CHARGESFOR: }\end{array}$ & $\begin{array}{l}\text { THE LAW DOESNOT PROVIDE } \\
\text { PROTECTION FROM CHARGESFOR: }\end{array}$ \\
\hline \multirow{2}{*}{ Simple possession (personal use) } & Selling illegal drugs (t rofficling) \\
\hline & Offences otherthan drug possession \\
\hline \multirow[b]{2}{*}{$\begin{array}{c}\text { Violation of pre-trial release, probation } \\
\text { order, conditional sentence, or parole related } \\
\text { to simple possession }\end{array}$} & Any outstanding arrest warrants \\
\hline & $\begin{array}{c}\text { Violation of pre-trial release, probation order, } \\
\text { conditional sentence, or parole for an offence } \\
\text { other than simple possession }\end{array}$ \\
\hline
\end{tabular}

\section{Figure 1}

Wallet cards outlining the tenets of the GSDOA that are distributed in the community.

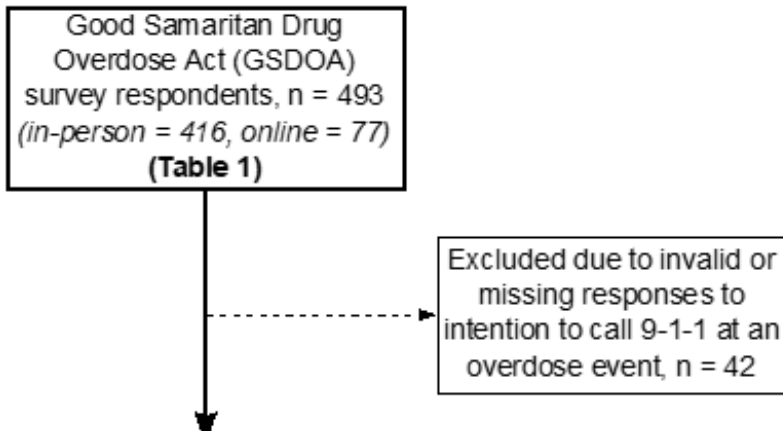

Sample who reported their intention to call 9-1-1 at an overdose event, $n=451$

(Table 2)

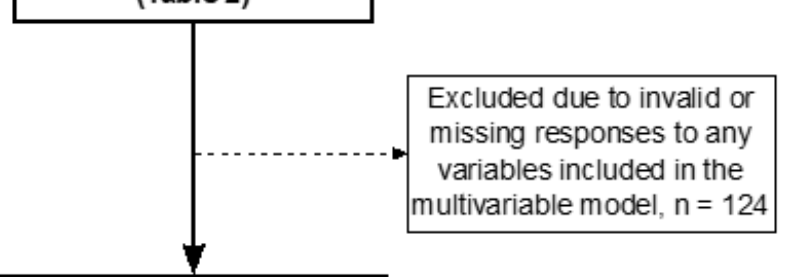

Sample with valid responses

to all variables in the

multivariable model, $n=327$

(Table 3)

Figure 2

Outline of the study sample used for each analysis. 


\section{Supplementary Files}

This is a list of supplementary files associated with this preprint. Click to download.

- AdditionalFile1.pdf

- AdditionalFile2.pdf 